\title{
Tiere und Pilze in Frankfurts Botanischen Gärten - ein Bürgerwissenschaftsprojekt
}

https://www.inaturalist.org/projects/tiere-und-pilze-in-frankfurts-botanischen-garten

In der vorangegangenen Ausgabe von „Der Palmengarten " berichteten wir ausführlich über dieses Projekt. Die Saison ist abgeschlossen, im nächsten Jahr geht es aber weiter. Wir möchten erneut alle daran Interessierten dazu aufrufen, eigene Beobachtungen von Tieren und Pilzen in Frankfurts Botanischen Gärten auf inaturalist einzustellen. Bis zum 29.11. 2019 wurden 1604 Beobachtun-

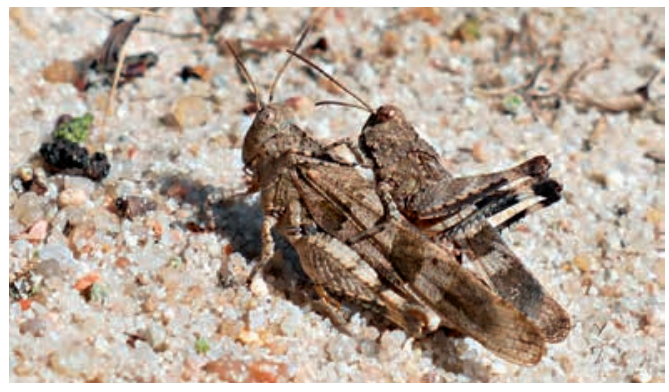

Abb. 1: Blauflügelige Ödlandschrecke (Oedipoda caerulescens). (Foto: H. STEINecke) gen, darunter 355 verschiedene Arten, hochgeladen. Es wurden 2783 Bestimmungen zu den eingestellten Beobachtungen abgegeben. Die meisten Einträge erhielt die Honigbiene (Apis mellifera, 46 Beobachtungen), gefolgt von Distelfalter (Vanessa cardui, 27), Stahlblauem Grillenjäger (Isodontia mexicana, 27) und Teichhuhn (Gallinula chloropus, 23)

\section{Literatur}

Schmidt, M., König, A., Steinecke, H. \& Zizka, G. 2019: Tiere und Pilze in Frankfurts Botanischen Gärten - ein Bürgerwissenschaftsprojekt. - Palmengarten 83: 54-59.

\section{Anschrift der Autorin}

Dr. Hilke Steinecke, Palmengarten Frankfurt, Siesmayerstraße 61, 60323 Frankfurt, E-Mail: hilke.steinecke@stadt-frankfurt.de

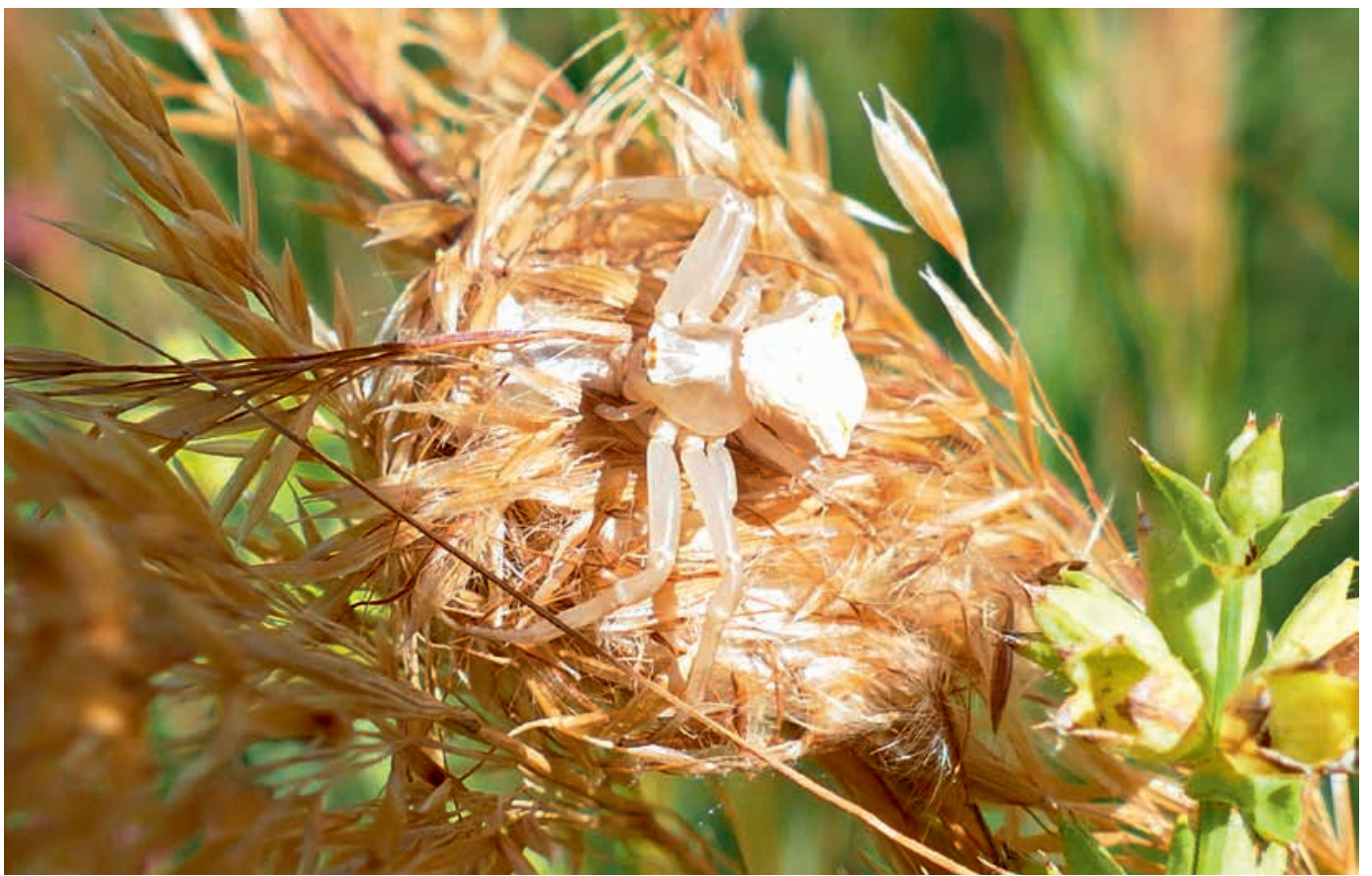

Abb. 2: Gehöckerte Krabbenspinne (Thomisus onustus). (Foto: H. STEInecke) 